\title{
PRÁTICAS DE LEITURA COMO RECURSO DIDÁTICO NO ENSINO DA HISTÓRIA LOCAL
}

\author{
READING PRACTICES AS A TEACHING RESOURCE IN TEACHING LOCAL HISTORY
}

\section{LAS PRÁCTICAS DE LECTURA COMO RECURSO DIDÁCTICO EN LA ENSEÑANZA DE LA HISTORIA LOCAL}

\author{
Ricardo Rodrigues Nascimento ${ }^{1}$ \\ Givaldo Cavalcanti ${ }^{2}$ \\ João Batista Gonçalves Bueno ${ }^{3}$
}

\begin{abstract}
Resumo: O presente artigo partiu da verificação de que os estudantes do ensino fundamental da Escola Estadual de Ensino Fundamental Professor Rangel (Ingá-PB) têm dificuldades de leitura e escrita. Por outro lado, entendemos que o estudo dos conteúdos históricos, realizado pela disciplina de História, contribuiu para a melhora das condições de ensino dessa escola básica. Por meio do estudo dessa área de conhecimento, pode-se produzir ações de leitura que estabeleceram relações entre fatos que ocorrem no presente com os ocorridos no passado. Entendemos que o processo de contextualização no cotidiano dos alunos na relação com as narrativas de memórias possibilitou, também o surgimento de práticas de leitura criadoras e inventivas, as quais tiveram um caráter multidimensional. Em relação aos aportes teóricos que utilizamos para o desenvolvimento desta pesquisa, destacam-se as concepções dos seguintes autores: W. Benjamin; José Carlos Reis; Maria Carolina B. Galzerani e Circe Bittencourt.
\end{abstract}

Palavras-chave: Ensino de história; leitura; narrativas de memória.

\begin{abstract}
This article started from the verification that elementary school students at the Professor Rangel State Elementary School (Inga-PB) have difficulties in reading and writing. On the other hand, we understand that the study of historical contents carried out by the discipline of History contributed to the improvement of teaching conditions in this elementary school. Because through the study of this area of knowledge, reading actions can be produced that establish relationships between facts that occur in the present and those that occurred in the past. We understand that the process of contextualization in the daily lives of students in relation to the narratives of memories also enabled the emergence of creative and inventive reading practices, which had a multidimensional character. Regarding the theoretical contributions that we used for the development of this research, the conceptions of the following authors stand out: W. Benjamin; José Carlos Reis; Maria Carolina B. Galzerani and Circe Bittencourt.
\end{abstract}

Keywords: History teaching; reading; memory narratives.

Resumen: Este artículo partió de la constatación de que los alumnos de la escuela primaria de la Escuela Primaria Estatal Profesor Rangel (Ingá-PB) tienen dificultades de lectura y escritura. Por otro lado, entendemos que el estudio de contenidos históricos, realizado por la disciplina de Historia, contribuyó al mejoramiento de las condiciones de enseñanza en esta escuela primaria. A través del estudio de esta área del conocimiento, es posible producir acciones de lectura que establezcan relaciones entre hechos que ocurren en el presente y los que ocurrieron en el pasado.

\footnotetext{
${ }^{1}$ Universidade Estadual da Paraíba.

${ }^{2}$ Universidade Estadual da Paraíba.

${ }^{3}$ Universidade Estadual da Paraíba.
} 
Entendemos que el proceso de contextualización en la vida cotidiana de los estudiantes en relación a las narrativas de los recuerdos también posibilitó el surgimiento de prácticas de lectura creativas e inventivas, las cuales tuvieron un carácter multidimensional. En cuanto a los aportes teóricos que utilizamos para el desarrollo de esta investigación, se destacan las siguientes concepciones de los autores: W. Benjamin; José Carlos Reis; Maria Carolina B. Galzerani y Circe Bittencourt.

Palabras clave: Enseñanza de la historia; leer; narrativas de memoria.

\section{Introdução}

Hoje em dia as escolas públicas, dentre tantas as adversidades que já enfrentam, sejam em aspectos físicos ou educacionais, também são submetidas a processos que avaliam o índice de qualidade educacional, a exemplo do Índice de Desenvolvimento da Educação Básica (IBED) e, no caso específico da Paraíba, também se acrescenta o Índice do Desenvolvimento da Educação da Paraíba (IDEPB). Tais avaliações em seus resultados sempre apontam um déficit de aprendizagem dos alunos, no que diz respeito às competências leitora e escritora. Estando nós professores, na realidade do dia a dia em sala de aula, não nos causa esforço para percebermos que estas avaliações em seus critérios, estão distantes das realidades dos alunos, embora saibamos que exista esta dificuldade em nossos alunos em leitura e escrita. Não é nosso objetivo neste artigo estabelecermos uma análise dessas avaliações, mas sim, a partir desta dificuldade em leitura, apontar caminhos para o estímulo da leitura através do ensino de História.

É nesta realidade educacional apresentada acima, que se encontra a Escola Estadual de Ensino Fundamental Professor Rangel, localizada na cidade do Ingá-PB, município do Agreste paraibano,

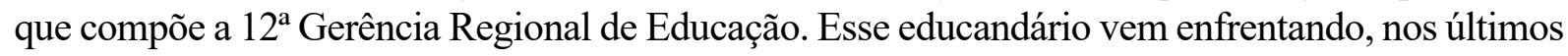
anos, o desafio de aumentar os índices de desenvolvimento da educação de seu alunado, tanto em nível estadual com o IDEPB, quanto em nível nacional com IDEB, pois a partir desses índices foi constatada uma deficiência nos alunos nas competências leitora e escritora. Segundo os resultados do IDEPB (PARAÍBA, 2018), apresentados a partir das avaliações aplicadas em $2017^{4}$, constatouse que $58 \%$ dos alunos que estavam cursando o $9^{\circ}$ ano se encontravam no nível básico ${ }^{5}$ de desempenho em Língua Portuguesa, como podemos observar na tabela abaixo:

\begin{tabular}{|c|l|l|l|}
\cline { 2 - 4 } \multicolumn{1}{c|}{ IDEPB } & $\mathbf{2 0 1 5}$ & $\mathbf{2 0 1 6}$ & $\mathbf{2 0 1 7}$ \\
\hline Abaixo do básico & $22,7 \%$ & $17 \%$ & $13 \%$ \\
\hline Básico & $45,5 \%$ & $47 \%$ & $58 \%$ \\
\hline Adequado & $27,3 \%$ & $31 \%$ & $23 \%$ \\
\hline Avançado & $4,5 \%$ & $6 \%$ & $6 \%$ \\
\hline
\end{tabular}

Tabela 1: Resultados do IDEPB - EEEF Prof. Rangel - 2015/2017

Fonte: IDEPB - http://www.avaliacaoparaiba.caedufjf.net/

A tabela 1 representa o resultado obtido pela Escola Estadual de Ensino Fundamental Professor Rangel, em Ingá - PB, no Sistema Estadual de Avaliação da Educação da Paraíba Avaliando IDEPB, nos anos de 2015 a 2017. Tal processo consiste numa proposta de avaliação institucional com foco no processo de ensino e aprendizagem, sobretudo no desempenho dos alunos em Língua Portuguesa e Matemática. Podemos observar pela tabela que a escola se encontra num processo de ascensão nos níveis Adequado e Avançado, porém ainda são altos os

\footnotetext{
${ }^{4}$ Fonte: IDEPB - https://avaliacaoparaiba.caedufjf.net/.

${ }^{5}$ Nessa avaliação conforme a nota obtida, cada aluno é classificado de acordo com as competências leitora e escritora, em uma escala dividida em quatro níveis que são: Abaixo do básico, Básico, Adequado e Avançado.
} 
índices dos níveis Básico e Abaixo do básico. Neste cenário percebemos que, hoje em dia, as escolas para atender aos critérios dessa avaliação, adotam métodos e recursos que possibilitem aos alunos atingirem os objetivos propostos por essas avaliações educacionais.

Deste modo, utilizando-se dos novos pressupostos para o ensino de História, apresentaremos no decorrer deste artigo uma experiência com narrativas de memórias dos estudantes e de seus familiares sobre o seu período de infância. Com esta atividade, buscamos explorar em sala de aula, não só o estímulo à leitura e produção textual, mas também a noção de tempo histórico na perspectiva de mudanças e permanências, por meio de narrativas de memórias dos estudantes sobre sua infância, bem como de entrevistas realizadas com os pais e avós sobre a sua infância e transcritas em narrativas. Em sequência, essas narrativas foram analisadas com os estudantes, para identificar costumes e práticas culturais, que permitissem associá-las ao contexto histórico do local e à possibilidade de relacioná-los ao conteúdo curricular de História.

\section{Novos métodos para uma nova história}

A possibilidade de hoje utilizarmos inúmeras fontes documentais para o ensino de História está relacionada ao surgimento da Nova História (nouvelle histoire), fundada pela Escola dos Annales, escola francesa que surgiu na década de 1920 e tendo por fundadores Lucien Febvre e Marc Bloch. A Escola dos Annales rompeu com os paradigmas da História Tradicional, que concebia a História por meio da narração dos eventos, presentes em documentos oficiais. Nesta História Tradicional, o trabalho do historiador seria de narrar os eventos de forma cronológica e linear, sem submetê-los a nenhuma análise ou questionamentos.

Frente a estes paradigmas, a Escola dos Annales apresenta um novo conceito de História, a história-problema, que não está preocupada em narrar os fatos tal como eles aconteceram, mas sim em questionar o presente, estabelecer um problema, um questionamento e assim estabelecer uma pesquisa histórica em busca da(s) resposta(s) no passado. Neste sentido Reis (2000) afirma que,

a partir da posição do problema o historiador distribui suas fontes, dá-lhes sentido e organiza as séries de dados que ele também terá construído. O texto histórico é o resultado de uma explícita e total construção teórica e não mais o resultado de uma narração objetivista [...] a pesquisa é feita a partir do problema que a suscitou: este vai guiar a seleção dos documentos, na seleção e construção das séries de eventos relevantes para a verificação das hipóteses, cuja construção ele exigirá (REIS, 2000, p. 74-75).

Em decorrência deste conceito de História, também foi necessário que a Escola dos Annales realizasse uma ressignificação dos conceitos de fato histórico e de fontes históricas. O fato histórico passou a ser entendido como uma construção, estabelecido por meio das questões, das hipóteses e dos problemas levantados pelo historiador a partir do presente, tendo por base a forma como este irá explorar essas fontes. Neste sentido as fontes documentais foram ampliadas, passando a ser entendidas como todo vestígio ou registro deixados pelo homem, sejam eles orais, escritos, audiovisuais ou materiais ${ }^{6}$. Desta forma o historiador, assume a liberdade de questionar, interpretar e explorar as fontes. E para ampliar o campo de compreensão destas, a Escola dos Annales se aproximou de outras ciências sociais como a economia, a sociologia, a antropologia dentre outras, fazendo uso de suas técnicas neste novo trato das fontes históricas (REIS, 2000).

\footnotetext{
${ }^{6}$ São exemplos de fontes: orais (entrevistas, depoimentos etc.); escritas (poemas, jornais, livros, cartas etc.); audiovisuais (fotografias, discos, filmes etc.); materiais (materiais arqueológicos, roupas, utensílios, móveis).
} 
Influenciados por esta nova concepção da História, o ensino de História no Brasil, desde a década de 90 do século XX, vem passando por reestruturações em seus currículos e métodos, de modo a propor novas possibilidades para o ensino de História em sala de aula, como demonstra Bittencourt (2008),

é fundamental que o professor faça emergirem as representações sociais que os alunos possuem sobre o tema a ser estudado, a fim de identificá-las e assim melhor organizar os conteúdos a ser apresentados, ampliar informações, explicitar com maior cuidado estudos comparativos e estabelecer com maior segurança os critérios para a escolha de materiais didáticos adequados (BITTENCOURT, 2008, p. 240).

Assim, entendemos que o professor dinamiza o ensino de História, quando, ao assumir a função de proporcionar aos estudantes um conhecimento significativo, desenvolve em sala de aula um ambiente propício para o ensino e a pesquisa. Na atividade de ensino e aprendizagem, como professores procuramos construir laços que unam teoria e prática, com o propósito de estabelecer um saber significativo para o estudante. Deste modo, compreendemos a sala de aula não só como um espaço educativo por natureza, mas também como espaço de conflitos, de relações sociais que precisam ser percebidos, evidenciados e explorados no processo educativo. A sala de aula é também, um lugar para onde convergem estudantes com vivências, com valores, com sentimentos, marcados por experiências que possuem um significado histórico.

Procuramos assim. no exercício da docência, observar e entender a sala de aula como um espaço plural, dinâmico e construtivo. Espaço este que, em sua essência, é um lugar de construção do conhecimento e de partilha de experiências, daí porque concebê-la também como um lugar onde fluem as sensibilidades. Compreendemos por sensibilidades os aspectos ressaltados por Pesavento (2005):

é a partir da experiência histórica pessoal que se resgatam emoções, sentimentos, ideias, temores ou desejos, o que não implica abandonar a perspectiva de que essa tradução sensível da realidade seja historicizada e socializada para os homens de uma determinada época. Os homens aprendem a sentir e a pensar, ou seja, a traduzir o mundo em razões e sentimentos (PESAVENTO, 2005, p. 128).

Desta forma, no percurso desta ação educativa para o ensino de História, buscamos proporcionar ao estudante um espaço em que ele possa expressar suas experiências, e que a escola seja uma formadora de sujeitos mais participativos em sua vida social. Para tanto, é preciso criar situações de aprendizagens significativas, que proporcionem a valorização de experiências. Por aprendizagem significativa adotamos o conceito desenvolvido por Ausubel, cuja

a essência do processo de aprendizagem significativa está em que ideias simbolicamente expressas sejam relacionadas de maneira não arbitrária e substantiva (não literal) ao que o aprendiz já sabe, ou seja, a algum aspecto relevante da sua estrutura de conhecimento (i. e., um subsunçor que pode ser, por exemplo, algum símbolo, conceito ou proposição já significativos). A aprendizagem significativa pressupõe que:

a. o material a ser aprendido seja potencialmente significativo para o aprendiz, i.e., relacionável a sua estrutura de conhecimento de forma não arbitrária e não literal (substantiva); 
b. o aprendiz manifeste uma disposição de relacionar o novo material de maneira substantiva e não arbitrária a sua estrutura cognitiva (AUSUBEL apud MOREIRA; MASINE, 1982, p. 13-14).

Porém, para estabelecer tal ação educativa, é preciso romper as práticas de cultura escolar ${ }^{7}$ já enraizada nesta escola em que desenvolvemos a pesquisa, por se preocupar em consolidar currículos que em nada refletem as realidades dos estudantes. Ao pensar assim a escola está imbuída de uma política dominante que impõe comportamentos e condutas que garantam o desenvolvimento da sociedade capitalista.

Desta forma, ao mobilizar a sociedade a favor da escola, boa parte da elite letrada estava também advogando que o trabalho é deseducativo para a criança, que as famílias pobres deveriam ser reformadas para bem educar, que a rua era uma grande ameaça à boa formação moral e, sobretudo, que as culturas pobres e do aprendizado na e pela experiência deveriam ser abandonadas a favor das racionalizadas e racionalizadoras culturas escolares. Aqui, como em muitos outros países, a reforma social sempre foi creditada à reforma da escola, ou seja, acreditou-se, e, ainda, acredita-se muito, que as transformações sociais no Brasil dependem, em última instância, da capacidade da escola em tornar disciplinadas, ordeiras e trabalhadoras as crianças pobres brasileiras (BERTUCCI; FARIA FILHO; OLIVEIRA, 2010, p. 47).

Levando em consideração esses aspectos, faz-se necessário romper com esta ação racionalizadora da escola, que concebe o aluno como um sujeito incompleto e carente de conhecimento, necessitado de ser disciplinado. Opondo-se a esta prática, espera-se que a escola seja um lugar, que compreenda e acolha a realidade dos estudantes que a compõem, uma escola que pense "nas formas como os sujeitos escolares se apropriam das tradições, das culturas nas quais estão imersos" (BERTUCCI; FARIA FILHO; OLIVEIRA, 2010, p. 57).

Porém, estabelecer um ambiente colaborativo em sala de aula está cada vez mais difícil. A estrutura curricular e organizacional das escolas está condicionada a individualizar e disciplinar a participação desses estudantes no processo educativo. Isto porque a escola como instituição educacional, ao longo da história, consolidou-se como um órgão burocrático e disciplinador. Chervel (1990) em seus estudos já indicava que ela possui "finalidades mais sutis de socialização do indivíduo no sentido amplo, da aprendizagem da disciplina social, da ordem, do silêncio, da higiene, da polidez, dos comportamentos docentes" (CHERVEL, 1990, p. 188). Tardif e Lessard (2014) já a identificam como a serviço de interesses ideológicos, em que,

a escola teria por objetivo, então, inculcar valores de obediência, de empenho, de perseverança e de disciplina nas crianças, ao mesmo tempo, mergulhandoas numa primeira organização do trabalho coletivo, do trabalho abstrato, planejado em função de tempos e objetivos que só têm sentido dentro do sistema produtivo. A escola seria a prefiguração, assim, de uma primeira organização científica do trabalho (TARDIF; LESSARD, 2014, p. 60).

\footnotetext{
${ }^{7} \mathrm{O}$ conceito de cultura escolar nesta pesquisa tem por fundamento o pensamento de Dominique Julia (2001) que concebe a "cultura escolar como um conjunto de normas que definem conhecimentos a ensinar e condutas a inculcar, e um conjunto de práticas que permitem a transmissão desses conhecimentos e a incorporação desses comportamentos; normas e práticas coordenadas a finalidades que podem variar segundo as épocas (finalidades religiosas, sociopolíticas ou simplesmente de socialização)" (JULIA, 2001, p. 10).
} 
Hoje prevalece nas escolas um currículo instituído por políticas educacionais que representam os interesses da classe dominante. Com isso temos de um lado a escola que tenta impor por meio desta cultura dominante um tipo de ideia, valores e comportamentos e do outro os estudantes com a sua cultura, valores e comportamentos divergentes. Neste embate, termina por não contemplar a realidade dos estudantes e proporcionar uma deficiência no processo de escolarização, principalmente nas escolas públicas.

Diante de tal situação de embates, o que fazer para superá-los? Que alternativas podem ser propostas para reverter esta situação, de modo que haja oportunidades para o afloramento da cultura e experiências dos estudantes de escolas públicas? Presumimos que ao encontrar tais respostas, elas não serão capazes de mudar por completo a concepção de escola no atual sistema educacional. Mas, refletir sobre estes questionamentos, conduz o professor a pensar em ações que enfrentem esta concepção de escola, formada por uma cultura escolar imposta pela classe dominante.

\section{Narrativas de memória: estímulo à leitura nas aulas de história}

O caminho que escolhemos para proporcionar aos estudantes uma aprendizagem significativa e estimularmos a leitura em seu processo educativo em sala de aula, deu-se por meio de narrativas de memórias dos estudantes e de seus familiares. Tais narrativas foram entendidas e analisadas "a partir de seus próprios prismas, incorporando o papel desempenhado tanto pela racionalidade como pela sensibilidade" (FRANÇA, 2020, p. 314), para na sequência analisá-las como parte do contexto histórico da História Local.

É comum no ensino de História Local de muitos municípios, serem abordadas sob o aspecto da história das famílias tradicionais e ricas. Entretanto, é preciso que se apresente uma proposta em que prevaleça a História do Local sob uma outra perspectiva. Que dê oportunidade para que sejam revelados fatos, acontecimentos e costumes que antes não foram abordados no estudo da História Local. Que coloque no cerne desta história aqueles que são esquecidos, mas que foram e são também sujeitos construtores desta História Local.

No entanto, trabalhar com memória no ensino de História, remete-nos a uma ação educativa que permite revolver o passado a partir de questões do presente e, ao mesmo tempo, este passado revolvido lançar questões para o presente. Esta ação nos leva a descobertas capazes de não só alterarmos o que já concebemos no presente, mas também o passado, numa relação de mão dupla, como afirma Walter Benjamin em sua Tese IV no artigo "Sobre o conceito de História", "a relação entre hoje e ontem não é unilateral: em um processo eminentemente dialético, o presente ilumina o passado, e o passado iluminado torna-se uma força no presente" (LÖWY, 2005, p. 61).

De acordo com os escritos de Walter Benjamin (2012b; 2012c), a rememoração é um ato de resistência às forças dominantes, um ato de produção de significados coletivos, ou seja, o ato de realizar a História. Isto porque ao realizar a rememoração, Benjamin estabelece uma crítica ao historicismo, que tem por ideal uma História universal, linear e que os acontecimentos ocorrem de forma cronológica e progressiva.

Esta ideia linear da História, proposta pelo historicismo, é desconstruída por Benjamin, ao demonstrar que a rememoração é o elo estabelecido entre o passado e o presente, sabendo que este presente está repleto de resquícios do passado que, muitas vezes, são silenciados por manobras daqueles que estão no poder e que buscam sempre silenciar os vencidos. Os vencidos precisam entender os sinais do passado contidos no presente e se apropriar como instrumento de luta contra as desigualdades, violências e preconceitos impostos pelos vencedores. Daí porque, a relevância de trazer estes silêncios do passado ao presente, pois quando se acessa o passado, através da memória, não o faz sem reescrevê-lo e vinculá-lo a experiências do seu presente (XIMENES ALVES, 2018). 
Tal movimento de articulação entre o passado e o presente nos é apresentado por Walter Benjamin, na Tese VI de "Sobre o conceito de História", ao afirmar que,

Articular historicamente o passado não significa conhecê-lo 'tal como de fato foi'. Significa apropriar-se de uma recordação, como ela relampeja no momento de um perigo. Para o materialismo histórico, trata-se de fixar uma imagem do passado da maneira que ela se apresenta inesperadamente ao sujeito histórico, no momento do perigo. O perigo ameaça tanto a existência da tradição como os que a recebem. Ele é um e o mesmo para ambos: entregar-se às classes dominantes, como seu instrumento. Em cada época, é preciso arrancar a tradição ao conformismo, que quer apoderar-se dela. [...] O dom de despertar no passado as centelhas da esperança é privilégio exclusivo do historiador convencido de que tampouco os mortos estarão em segurança se o inimigo vencer. E esse inimigo não tem cessado de vencer (BENJAMIN, 2012c, p. 243-244).

Neste sentido, a memória precisa ser analisada de modo a tratá-la em uma posição de diálogo com outros saberes, com elementos capazes até de questionar o próprio olhar do historiador diante dos fatos. De modo que a memória seja "capaz de dinamizar a visão de produção de conhecimentos, entrecruzando diferentes espaços, diferentes temporalidades, diferentes sujeitos, diferentes visões do mundo (a da criança e a do filósofo, por exemplo)" (GALZERANI, 2009, p. 21).

Ainda de acordo com Galzerani (2009), o ato de rememorar é um trabalho que parte do presente para o passado a partir da recordação, em que o sujeito que rememora se aproxima daquilo que ele está rememorando. Esta rememoração promove, então, um entrecruzamento de sua visão do presente com a sua visão da época rememorada. Nesta perspectiva, para proporcionar a rememoração dos estudantes, buscamos por meio da literatura de Cordel com temática sobre a infância, estabelecermos uma relação entre a realidade dos estudantes e os conteúdos estabelecidos no currículo escolar, ao passo que as leituras desses cordéis vieram contribuir para ampliar o conhecimento sobre a necessidade de estabelecer as relações entre o passado e o presente nesse processo. Entendemos que essas atividades, a partir de questões do presente, contribuíram para que os estudantes, na correlação com o passado, estabelecessem correspondências que possibilitaram a apropriação da aprendizagem.

Sendo assim, a leitura do cordel "Brinquedos populares", de autoria de Ana Raquel Campos, possibilitou "trazer imagens do passado vivido, como opção de questionamento das relações e sensibilidades sociais, como uma busca atenciosa relativa aos rumos a serem construídos, sobretudo, no presente" (GALZERANI, 2021, p. 73-74). Rememorar o passado vivido dos alunos e seus familiares nos abriu a possibilidade de relacionar diferentes experiências e sentimentos vividos em diversas gerações.

Em análise dessas narrativas de memória, foram identificados fatos relevantes que distinguem bem as diferenças temporais entre cada geração. Nos relatos dos idosos sobre sua infância, identifica-se que estes ao falarem sobre a infância adentram também a narrar sobre a adolescência. Isso só demonstra que não há muita diferença entre uma fase e outra de sua vida. Nesses relatos percebemos que entre diversão, trabalho e estudo, sempre prevalecia o trabalho. O trabalho se caracterizava em ajudar os pais, como, por exemplo, se este era agricultor o trabalho se dava nas plantações. Outro aspecto comum no relato dessa geração (avós), é que estes em sua maioria ao atingirem a maioridade, destinam-se a ir em busca de trabalho em outras regiões, a exemplo de São Paulo e Rio de Janeiro. 
Já com relação às narrativas dos pais, prevalecem relatos de uma vida urbana, pois encontramos registros de "brincadeiras de rua"8 e participações em festas da cidade. Constatamos em alguns relatos dessa geração que havia uma conciliação entre trabalho e escola, pois, em contraturno ao da escola, alguns dos participantes relatam que entre 11 e 12 anos, com o objetivo de complementar a renda familiar ou de adquirir um benefício próprio como roupas e calçados, trabalhavam de ajudante em comércios, lanchonetes, em faxinas de casas ou até vendendo balas, sorvetes e picolés em carrocinhas pelas ruas da cidade.

Nas narrativas dos estudantes, é possível constatar diversas realidades; enquanto uns relataram que tiveram uma infância tranquila, brincando com outras crianças, com jogos eletrônicos, jogando futebol, assistindo TV e estudando, outros relataram que passaram por dificuldades financeiras ou foram morar com os avós devido ao divórcio dos pais ou porque estes foram trabalhar em outra cidade.

Ao realizarmos a correlação das narrativas de memória com o contexto histórico referente a elas, podemos constatar que as narrativas dos avós, as memórias se referem às décadas de 1960 e 1970. Nesse período o Brasil era governado por uma ditadura civil-militar, que, além de reprimir os direitos constitucionais democráticos, priorizava os interesses capitalistas, concentrando os investimentos em industrialização e urbanização nas regiões do Rio de Janeiro e São Paulo. Fato este que impulsionou no período grande fluxo migratório, principalmente da população nordestina. Isto leva a relacionar ao fato de que nas narrativas dos avós, estes ao atingirem a maioridade migravam para os centros urbanos citados, em busca de trabalho.

Em relação aos pais, é possível identificar que as narrativas compreendem o período entre as décadas de 1980 e 1990. Desta forma, evidenciamos o fato que em algumas narrativas, estes quando crianças exerciam algum tipo de trabalho para ajudar a complementar a renda familiar. É possível estabelecer uma relação com o fato de que, entre a década de 80 e início dos anos 90, ocorreu um período de seca aqui na Paraíba, o que impossibilitava os meios de garantir o sustento da família por meio da agricultura. Em consequência, os pais migravam para a região Sudeste em busca de emprego e de lá enviavam recursos para garantir o sustento da família. Daí porque neste período muitas crianças também exercerem algum tipo de serviço ou trabalho para complementar a renda familiar.

Na continuidade desta análise temporal, percebemos que nas narrativas dos estudantes, não é mencionada nenhuma relação com o trabalho, como foi citado nas gerações anteriores. Tal fato pode ser relacionado ao período de redemocratização do país após a ditadura civil-militar, sendo o marco representativo desse período a promulgação da Constituição de 1988. A partir da Constituição, derivam leis como o Estatuto da Criança e do Adolescente que institui políticas protetivas, estabelece o acesso das crianças à escola e a erradicação do trabalho infantil.

Portanto, ao aproximarmos as vivências de infância das três gerações, buscamos identificar as experiências citadas nas narrativas de memórias, pois como afirma Benjamin (2012a; 2012b), a experiência traz, além da informação temporal, cronológica, vivências das pessoas na relação com o mundo. Ao mesmo tempo proporcionamos aos estudantes uma releitura das narrativas de memória, ao possibilitarmos que eles estabelecessem relações entre os fatos rememorados e os contextos históricos de cada geração, sejam estes locais, regionais ou nacionais.

Nesta perspectiva, entendemos que o ensino da História Local apresenta as condições propícias para tornar esses estudantes sujeitos participantes de seu processo educativo. Ao elegermos a História Local, aproximamos o ensino de história da realidade dos estudantes, pois "o fazem refletir e associar o seu dia a dia com os conteúdos escolares, os conteúdos tornam-se mais compreensíveis. Desta forma, os estudantes passam a gostar de aprender

\footnotetext{
${ }^{8}$ Brincadeiras do tipo pega-pega, pique, esconde, baleada, garrafão, pelada, dentre outros, foram citadas nas narrativas.
} 
história" (PAIM, 2007, p. 118). Nesta mesma perspectiva de aproximar o ensino de História da realidade dos estudantes, Bittencourt (2008) afirma:

\begin{abstract}
A compreensão do entorno do aluno, identificando o passado sempre presente nos vários espaços de convivência - escola, casa, comunidade, trabalho e lazer - , e igualmente situar os problemas significativos da história do presente [...] geralmente se liga à História do cotidiano ao fazer das pessoas comuns participantes de uma história aparentemente desprovida de importância e estabelecer relações entre os grupos sociais de condições diversas que participaram de entrecruzamento de histórias, tanto no presente como no passado (BITTENCOURT, 2008, p. 168).
\end{abstract}

Deste modo, explorar o entorno do estudante abre a possibilidade para o professor fazer uso de inúmeras fontes documentais, sejam elas escritas, iconográficas ou orais. Explorar estas fontes em sala de aula, questioná-las, contribui para o desenvolvimento de uma aprendizagem significativa e a oportunidade de estabelecer laços significativos com a história de sua comunidade, e se desvencilhar do ensino tradicional da História.

\title{
Referências
}

BENJAMIN, Walter. Experiência e pobreza. In: Magia e técnica, arte e política: ensaios sobre literatura e história da cultura. 8. ed. São Paulo: Brasiliense, 2012a. p. 123-128.

BENJAMIN, Walter. O narrador. In: Magia e técnica, arte e política: ensaios sobre literatura e história da cultura. 8. ed. São Paulo: Brasiliense, 2012b. p. 213-240.

BENJAMIN, Walter. Sobre o conceito de história. In: Magia e técnica, arte e política: ensaios sobre literatura e história da cultura. 8. ed. São Paulo: Brasiliense, 2012c. p. 241-252.

BERTUCCI, Liane Maria; FARIA FILHO, Luciano Mendes de; OLIVEIRA, Marcus Aurelio Taborda de. Edward P. Thompson: história e formação. Belo Horizonte: Ed. UFMG, 2010.

BITTENCOURT, Circe Maria Fernandes. Conteúdos históricos: como selecionar? In: BITTENCOURT, C. M. F. Ensino de história: fundamentos e métodos. 2. ed. São Paulo: Cortez, 2008. p. 135-179.

CHERVEL, André. História das disciplinas escolares: reflexões sobre um campo de pesquisa. Teoria \& Educação, n. 2, p. 177-229, 1990.

FRANÇA, Cyntia Simioni. Memória como meio de produção de conhecimentos históricos. Revista Memória em Rede, Pelotas, v. 12, n. 23, p. 298-316, jul./dez. 2020. Disponível em: https://periodicos.ufpel.edu.br/ojs2/index.php/Memoria/article/view/14858. Acesso em: 22 dez. 2020.

GALZERANI, Maria Carolina Bovério. A produção de saberes históricos escolares: o lugar das memórias. In: KOYAMA, A. C.; GALZERANI, J. C.; PRADO, G. V. T. (Org.). Imagens que lampejam: ensaios sobre memória, história e educação das sensibilidades. Campinas: FE/UNICAMP, 2021. p. 66-81. 
GALZERANI, Maria Carolina Bovério. Memória, história e tempo: perspectivas teóricometodológicas para a pesquisa em ensino de história. Cadernos do CEOM-Memória, História e Educação, ano 21, n. 28, p. 15-31, 2009. Disponível em: https://bell.unochapeco.edu.br/revistas/index.php/rcc/article/view/152. Acesso em: 22 dez. 2020.

JULIA, Dominique. A cultura escolar como objeto histórico. Revista Brasileira de História da Educação, v. 1, n. 1, p. 9-43, fev. 2001. Disponível em: http://periodicos.uem.br/ojs/index.php/rbhe/article/view/38749. Acesso em: 20 jul. 2020.

LÖWY, Michael. Walter Benjamin: aviso de incêndio: uma leitura das teses "Sobre o conceito de história”. São Paulo: Boitempo, 2005.

MOREIRA, Marco Antonio; MASINI, Elcie F. Salzano. Aprendizagem significativa: a teoria de David Ausubel. São Paulo: Moraes, 1982.

PAIM, Elison Antonio; PICOLLI, Vanessa. Ensinar história regional e local no ensino médio: experiências e desafios. História \& Ensino, Londrina, v. 13, p. 107-126, set. 2007.

PARAÍBA (Estado). Avaliando IDEPB. Avaliação Paraíba, 2018. Disponível em: https://avaliacaoparaiba.caedufjf.net/. Acesso em: 22 de agosto de 2018.

PESAVENTO, Sandra Jatahy. Sensibilidades no tempo, tempo das sensibilidades. Revista Tempos Acadêmicos, Criciúma, n. 03, p. 127-134, 2005.

REIS, José Carlos. Escola dos Annales: a inovação em história. São Paulo: Paz e Terra, 2000.

TARDIF, Maurice; LESSARD, Claude. $O$ trabalho docente: elementos para uma teoria da docência como profissão de interações humanas. 9. ed. Petrópolis: Vozes, 2014.

XIMENES ALVES, Claudia. Infância, brincar e memória de infância em Walter Benjamin: categorias de estudo passíveis de associação à formação e à prática docente ligadas à infância no contexto contemporâneo. Aprender - Caderno de Filosofia e Psicologia da Educação, Vitoria da Conquista, n. 19, ano XII, p. 76-94, jan./jun. 2018. Disponível em: https://doi.org/10.22481/aprender.v0i19.4494. Acesso em: 09 out. 2020.

\section{Sobre os autores}

Ricardo Rodrigues Nascimento: Professor na EEEF. Prof. Rangel (Ingá-PB) e na EMEF Prof. Luiz. G. Burity (Soledade-PB). Possui graduação em Lic. Plena em História pela Universidade Federal de Campina Grande e graduação em Comunicação Social com Habilitação em Jornalismo pela Universidade Estadual da Paraíba. Possui Especialização em Teoria e Metodologia do Ensino em História e Especialização em Fundamentos da Educação: Práticas Pedagógicas Interdisciplinares, ambas pela Universidade Estadual da Paraíba. Mestrando do Programa de Pós-Graduação em Formação de Professores pela Universidade Estadual da Paraíba. Desenvolve pesquisas nas áreas de História, Metodologia do ensino de História, livro didático de História e Educação Patrimonial. Integra o grupo de estudos Rastros-PB: História, Memória e Educação, com sede no Núcleo de Documentação Histórica (NDH) da UEPB. E-mail: ricardo.ingapb@gmail.com. 
Givaldo Cavalcanti: Possui graduação em Licenciatura Plena em História pela Universidade de Pernambuco (2004) e Especialização em História de Pernambuco, também pela Universidade de Pernambuco (2005-2006). Possui graduação em Comunicação Social com Habilitação em Jornalismo pela Universidade Estadual da Paraíba (2011). Mestrando do Programa de PósGraduação em Formação de Professores (PPGPFP) pela Universidade Estadual da Paraíba. Atuou como repórter do jornal Diário da Borborema (2010-2012), e no Jornal da Paraíba (2012-2015), ambos em Campina Grande. Atualmente atua como jornalista na Coordenadoria de Comunicação da Universidade Estadual da Paraíba, em Campina Grande. Desenvolve pesquisas nas áreas de História, ensino de História, livro didático de História, cultura da convergência, tipos de texto, hipertexto, conectividade e fronteiras, tecnologias relacionadas à educação e objetos educacionais digitais. Integra o grupo de estudos Rastros-PB: História, Memória e Educação, com sede no Núcleo de Documentação Histórica (NDH) da UEPB.

E-mail: mailto:gcavalcantifilho@gmail.com.

João Batista Gonçalves Bueno: Doutor e Mestre em Educação pela Universidade Estadual de Campinas, Bacharel e Licenciado em História pelo IFCH- UNICAMP. Atualmente é professor adjunto da Universidade Estadual da Paraíba, lotado no Departamento de História, Campus III - Guarabira - PB. Membro permanente do Programa de pós-graduação em Formação de Professores da Universidade Estadual da Paraíba. Membro permanente do Programa de pósgraduação em História da Universidade Federal da Paraíba. Pesquisador do grupo de pesquisa "Rastros " vinculado à Universidade São Francisco. Líder do grupo de pesquisa Rastros- PB, Pesquisador do grupo de pesquisa Kairós, vinculado à Unicamp. Coordenador de área de História da Residência Pedagógica da UEPB- Campus III. Faz pesquisas na área de Ensino de História, memória, artes e decolonização do saber, do poder e do ser, atuando principalmente nos seguintes temas inter-relacionados: educação, história, imagens, artes plásticas, currículos inter-culturais e relações étnico-raciais.

E-mail: joaobgbueno@hotmail.com. 